\title{
Control of fetal lung development in the rabbit
}

\author{
MALCOLM L. CHISWICK, ALI AHMED, P. M. B. JACK, and R. D. G. MILNER \\ From the Departments of Child Health and Pathology, University of Manchester, Manchester
}

\begin{abstract}
Chiswick, M. L., Ahmed, A., Jack, P. M. B., and Milner, R. D. G. (1973). Archives of Disease in Childhood, 48, 709. Control of fetal lung development in the rabbit. In a series of experiments, one rabbit fetus of a litter was decapitated in utero on day 24 of gestation and allowed to develop for a further 5 days. One effect of fetal decapitation was a reduction in the concentration of osmiophilic inclusion bodies in the type II pneumocytes of the lung. However, certain physical properties of the lung which depend on the presence of a surface active alveolar lining were normal. When $50 \mu \mathrm{g}$ tetracosactrin was given to the fetus subcutaneously at the time of decapitation, there was no reduction in the concentration of inclusion bodies. It is suggested that though the production of surface active material in the pneumocyte is controlled at least in part by fetal adrenocortical hormones, the extrusion of this material into the alveolar space may be subject to other control. This may have important implications for the prophylactic treatment of the respiratory distress syndrome in premature babies by antepartum maternal glucocorticoid therapy.
\end{abstract}

The presence of a surface active lining which stabilizes alveoli and prevents their collapse on expiration is a prerequisite for fetal adaptation to extrauterine existence. It is not until the onset of ventilation and the appearance of a gas/liquid interface that the lining is fully formed. The principle component of the lining is dipalmitoyl lecithin, and there is evidence that the osmiophilic inclusion bodies present in the type II pneumocytes represent surface active material that has been produced and stored in the cell (Buckingham et al., 1966; Kikkawa, Motoyama, and Cook, 1965). Pulmonary surface activity is first detected in late fetal life (Buckingham and Avery, 1962; Gluck et al., 1967). There is evidence that the respiratory distress syndrome of premature babies is associated with the absence of a normal surface active alveolar lining (Avery and Mead, 1959).

Liggins (1969) showed that when premature parturition was induced by the infusion of glucocorticoids to fetal lambs the animals survived, and when sacrificed later their lungs remained partially expanded. Stimulated by this finding, other workers showed that the administration of glucocorticoids to fetal rabbits (Kotas and Avery, 1971) and fetal lambs (DeLemos et al., 1970) accelerated the development of pulmonary surface properties. These findings culminated in a study

Received 24 January 1973. which suggested that the administration of betamethasone to women for at least 24 hours before delivery might have lowered the incidence of the respiratory distress syndrome in those infants born before 32 weeks' gestation (Liggins and Howie, 1972). Knowledge of those factors which control the development of the surface active alveolar lining may put on a rational basis therapeutic effort to accelerate pulmonary maturation. We have studied the implication that endogenous fetal glucocorticoids contribute to normal development of pulmonary surface properties in the rabbit. Previous experiments have shown that fetal adrenal hypoplasia occurs in the absence of the fetal pituitary gland (Jost and Picon, 1970). In a series of experiments the effect of fetal decapitation on the development of rabbit lung was studied.

\section{Materials and methods}

Dutch rabbits reared in the departmental animal house were used. The gestational age of a fetus was calculated from the time of artificial insemination of the doe. At laparotomy, under general anaesthesia, the uterus of a 24-day pregnant doe was exposed. One fetus of the litter was decapitated in utero as described by Bearn (1968). On day 29 the doe was killed by a blow on the back of the head and the uterus was exposed. A ligature was firmly tied around the neck of each fetus through the uterine wall to prevent ventilation. The fetuses were delivered by hysterotomy and immediately killed by a blow on the back of the head. The 
decapitated fetus was compared with control littermates in terms of lung histology and certain pulmonary physical properties. In a further series of experiments, $50 \mu \mathrm{g}$ tetracosactrin (Synacthen Depot, Ciba) was administered subcutaneously into the scapular region of the experimental fetus at the time of decapitation. After harvesting on day 29 as described above, the lungs were examined histologically.

Histology. Lung tissue was obtained from the decapitated fetus and a control littermate selected at random. Sections $1 \mu \mathrm{m}$ thick were prepared (Gandy, Jacobson, and Gairdner, 1970) and stained with $0.5 \%$ p-phenylene diamine (British Drug Houses, Poole) in $70 \%$ alcohol (G. Gandy, personal communication, 1972). The number of type II pneumocytes and osmiophilic inclusion bodies per $100 \mu \mathrm{m}^{2}$ were counted using light microscopy at a magnification $\times \mathbf{4 0 0}$ and an eyepiece grid. The average number of inclusion bodies per type II pneumocyte was calculated. Four sections were examined from each block, and four areas were counted on each section.

Pressure-volume studies. With the chest wall intact, the deflation limb of the pressure-volume curve was determined for the lungs of the decapitated fetus and 5 littermate controls nearest in headless body weight. The apparatus used was described by Avery, Frank, and Gribetz (1959). The pressure-volume curve was described as the volume of air ( $\mathrm{ml}$ ) retained per $\mathrm{g}$ lung weight at a distending pressure of $35 \mathrm{~cm} \mathrm{H} \mathrm{H}_{2} \mathrm{O}\left(\mathrm{V}_{\max } / \mathrm{g}\right)$; the volume of air retained by the lungs on deflation to a pressure of $10 \mathrm{~cm} \mathrm{H}_{2} \mathrm{O}$ expressed as a percentage of $\mathrm{V}_{\max }\left(\% \mathrm{~V}_{\max }\right.$ at $\left.10 \mathrm{~cm} \mathrm{H}_{2} \mathrm{O}\right)$.

Bubble stability. The method described by Pattle (1958) was followed. The mean stability ratio of bubbles squeezed from the lungs of the decapitated fetus and 5 littermates nearest in headless body weight was calculated. 20 to 30 bubbles from each pair of lungs were examined.

\section{Results}

Light microscopy showed the presence of well-

formed alveoli in the lungs of both experimental and control fetuses, but there was considerable variation in alveolar size in different sections and in adjacent parts of a single section. The amount of osmiophilic inclusion bodies in the alveolar spaces of experimental and control fetuses appeared similar. Intra-alveolar inclusions were not counted as there was considerable variation in their concentration both within and between sections. The number of inclusion bodies per $100 \mu \mathrm{m}^{2}$ and inclusion bodies per type II pneumocyte was significantly less in the lungs of the decapitated fetuses compared with control fetuses $(P<0.001)$ (Table I and Fig.). However, the concentration of inclusion bodies per $100 \mu \mathrm{m}^{2}$ and inclusion bodies per type II pneumocyte in the fetuses that had received tetracosactrin at the time of decapitation was similar to that of control fetuses (Table II).

There was no significant difference between decapitated and control fetuses in terms of the parameters derived from the pressure-volume curves and the mean stability ratio of bubbles squeezed from the lungs (Table III).

\section{Discussion}

The reduction in concentration of inclusion bodies in the lungs of decapitated fetal rabbits, and the absence of this effect when tetracosactrin was administered at the time of decapitation suggests that fetal adrenocortical hormones and/or fetal adrenocorticotrophic hormone normally control the production of surfactant in the rabbit. Evidence that administration of 9-fluoro-prednisolone to fetal rabbits increases the concentration of pulmonary phosphoryl-choline-glyceride transferase, an enzyme necessary for the synthesis of dipalmitoyl lecithin, supports the concept of an adrenocortical hormonal influence on dipalmitoyl lecithin production (Farrell and Zachman, 1972).

TABLE I

Quantitative estimation of type II pneumocytes and inclusion bodies in four decapitation experiments

\begin{tabular}{|c|c|c|c|}
\hline & $\begin{array}{c}\text { Type II pneumocytes } \\
\left(\text { per } 100 \mu \mathrm{m}^{2}\right)\end{array}$ & $\begin{array}{l}\text { Inclusion bodies } \\
\left(\text { per } 100 \mu \mathrm{m}^{2}\right)\end{array}$ & $\begin{array}{l}\text { Inclusion bodies } \\
\text { (per type II pneumocyte) }\end{array}$ \\
\hline $\begin{array}{l}\text { Decapitated } \\
\text { Control } \\
\text { Decapitated } \\
\text { Control } \\
\text { Decapitated } \\
\text { Control } \\
\text { Decapitated } \\
\text { Control }\end{array}$ & $\begin{array}{l}74 \pm 5 \\
70 \pm 3 \\
65 \pm 3 \\
74 \pm 2 \\
87 \pm 4 \\
81 \pm 4 \\
92 \pm 6 \\
90 \pm 7\end{array}$ & $\begin{array}{c}59 \pm 7 \\
128 \pm 18 \\
53 \pm 5 \\
160 \pm 10 \\
45 \pm 3 \\
101 \pm 7 \\
28 \pm 3 \\
63 \pm 6\end{array}$ & $\begin{array}{l}0 \cdot 8 \pm 0 \cdot 07 \\
1 \cdot 8 \pm 0.25^{\star} \\
0 \cdot 8 \pm 0.06 \\
2 \cdot 2 \pm 0 \cdot 13^{\star} \\
0.5 \pm 0.04 \\
1 \cdot 3 \pm 0.22^{\star} \\
0 \cdot 3 \pm 0.04 \\
0.7 \pm 0.04^{\star}\end{array}$ \\
\hline
\end{tabular}

Mean $( \pm S E)$ of 16 observations in each lung is shown.

$\star \mathbf{P}<0.001$. 
(a)

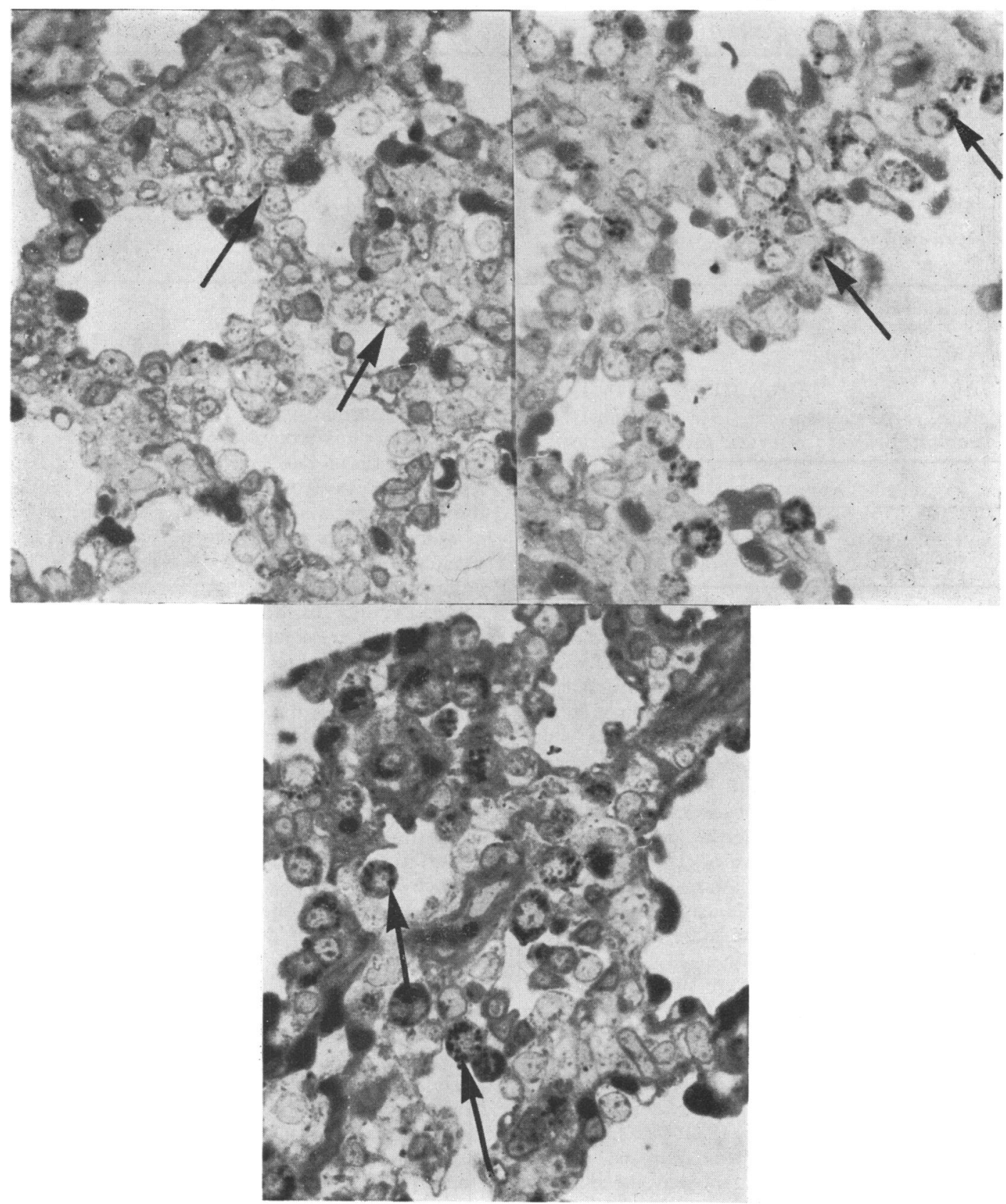

(c)

FIG.-Lung from rabbit fetus showing osmiophilic inclusion bodies (arrows) within type II pneumocyte. (a) Decapitated fetus showing reduced numbers of inclusion bodies compared with both (b) control and (c) decapitated fetus treated with tetracosactrin. $(\times 500$. 
TABLE II

Quantitative estimation of type II pneumocytes and inclusion bodies in four decapitation plus tetracosactrin experiments

\begin{tabular}{|c|c|c|c|}
\hline & $\begin{array}{l}\text { Type II pneumocytes } \\
\left(\text { per } 100 \mu \mathrm{m}^{2}\right)\end{array}$ & $\begin{array}{l}\text { Inclusion bodies } \\
\left(\text { per } 100 \mu m^{2}\right)\end{array}$ & $\begin{array}{l}\text { Inclusion bodies } \\
\text { (per type II pneumocyte) }\end{array}$ \\
\hline $\begin{array}{l}\text { Decapitated + tetracosactrin } \\
\text { Control } \\
\text { Decapitated + tetracosactrin } \\
\text { Control } \\
\text { Decapitated + tetracosactrin } \\
\text { Control } \\
\text { Decapitated + tetracosactrin } \\
\text { Control }\end{array}$ & $\begin{array}{l}86 \pm 3 \\
82 \pm 4 \\
62 \pm 3 \\
69 \pm 2 \\
90 \pm 7 \\
94 \pm 9 \\
82 \pm 4 \\
90 \pm 5\end{array}$ & $\begin{array}{l}112 \pm 10 \\
123 \pm 17 \\
124 \pm 15 \\
166 \pm 10 \\
117 \pm 14 \\
85 \pm 6 \\
115 \pm 8 \\
153 \pm 9\end{array}$ & $\begin{array}{l}1 \cdot 3 \pm 0 \cdot 21 \\
1 \cdot 5 \pm 0 \cdot 22^{\star} \\
2 \cdot 0 \pm 0 \cdot 13 \\
2 \cdot 4 \pm 0 \cdot 24^{\star} \\
1 \cdot 3 \pm 0 \cdot 22 \\
0 \cdot 9 \pm 0 \cdot 09^{\star} \\
1 \cdot 4 \pm 0 \cdot 13 \\
1 \cdot 7 \pm 0 \cdot 16^{\star}\end{array}$ \\
\hline
\end{tabular}

Mean ( \pm SE) of 16 observations in each lung is shown.

^Not significant.

TABLE III

Physical properties (means $\pm S E$ ) of lungs from decapitated rabbit fetuses and littermate controls

\begin{tabular}{l|c|c}
\hline & Decapitated (no. = 7) & Control (no. = 35) \\
\hline$V_{\max } / \mathrm{g}$ & $3 \cdot 1 \pm 0.3$ & $2 \cdot 8 \pm 0 \cdot 2^{\star}$ \\
$\%$ Vmax at $10 \mathrm{~cm} \mathrm{H} \mathrm{H}_{2} \mathrm{O}$ & $71 \pm 2$ & $72 \pm 1^{\star}$ \\
Bubble stability ratio & $0.75 \pm 0.02$ & $0.77 \pm 0.03^{\star}$ \\
\hline
\end{tabular}

There is no conclusive evidence concerning the ability of maternal glucocorticoids to cross the placenta in the rabbit. There is good evidence that the sheep placenta is resistant to diffusion of cortisol (Beitins et al., 1970). That it is the fetus which controls pulmonary maturation is teleologically sound, because there is abundant evidence that, in some species at least, the fetal adrenal gland plays an important role in the initiation of labour (Cowie et al., 1964; Liggins and Kennedy, 1968). Naeye, Harcke, and Blanc (1971) showed that human anencephalic newborn infants with adrenal hypoplasia had less than half the mass of osmiophilic inclusion bodies in the type II pneumocytes compared with those who were not anencephalic. Though this supports our experimental results, it is difficult to explain the findings of Naeye et al. (1971) on the basis of reduced plasma levels of adrenocortical hormones during fetal life. The human placenta is relatively permeable to corticosteroids (Migeon, Bertrand, and Gemzell, 1961), and indeed the plasma levels of 17-hydroxycorticoids in the cord blood of anencephalic infants have been shown to be normal (Nichols, Lescure, and Migeon, 1958).

The determination of the stability of bubbles squeezed from the lungs correlates well with other methods of evaluating pulmonary surface properties (Gandy et al., 1968). Pattle (1958) showed that the mean stability ratio of bubbles derived from the lungs of normal term fetal rabbits was 0.572. Humphreys and Strang (1967) found that the mean stability ratio of bubbles from the lungs of 29-day fetal rabbits was 0.6 to 0.9 . Our results indicated the presence of surface active material in the lungs of both decapitated and control fetuses in amounts capable of forming a normal alveolar lining. These findings are supported by the normal pressurevolume results in both decapitated and control fetuses which are comparable with earlier reports in normal 29-day fetal rabbits (Humphreys and Strang, 1967; Kotas and Avery, 1971). Our results show that the relation of the osmiophilic inclusion body to the development of the surface active alveolar lining is not a simple one. A reduction in the concentration of inclusion bodies is consistent with the development of normal pulmonary surface properties; this suggests that a considerable reserve of surface active material is present in the lung parenchyma. At operation the neck was ligated before removal of the fetal head, and the communication between alveoli and the amniotic space was permanently lost. There is evidence that the phospholipids on the alveolar surface are rapidly metabolized (Tierney, Clements, and Trahan, 1967). Surface active material extruded into the alveolar space and ramaining there is therefore unlikely to be responsible for the normal pulmonary surface properties of the decapitated fetuses. Furthermore, the intra-alveolar concentration of inclusion bodies in experimental and control fetuses appeared similar on light microscopy.

The presence of ample parenchymal lecithin and a normal concentration of intracellular osmiophilic inclusion bodies has been reported in hyaline membrane disease occurring in infants of diabetic mothers (Boughton, Gandy, and Gairdner, 1970). 
This is consistent with the suggestion that the synthesis of lecithin, its extrusion into the alveolar space, and its subsequent metabolism may be controlled by different mechanisms.

Our results show that naturally occurring fetal adrenocortical hormones probably play a role in the development of pulmonary surface properties in the rabbit fetus, and support the concept that maternal glucocorticoid therapy may be beneficial in accelerating pulmonary maturation in the human fetus. However, it is probable that impairment of the mechanism by which surface active material is transported within the type II pneumocyte or discharged into the alveolus is as important as impaired synthesis of surface active material in certain types of respiratory distress syndrome of prematurity. This may prove a limiting factor in the role of maternal glucocorticoid therapy for the prevention of the respiratory distress syndrome in prematurely born offspring.

We are grateful to Professor J. A. Davis for his encouragement, to Mrs. R. V. Stafford for her assistance in the preparation of the histological material, and to the Medical Research Council for support. M.L.C. was supported by the Research Grants Committee of the United Manchester Hospitals.

\section{REFERENCES}

Avery, M. E., Frank, N. R., and Gribetz, I. (1959). The inflationary force produced by pulmonary vascular distension in excised lungs. The possible relation of this force to that needed to inflate the lungs at birth. fournal of Clinical Investigation, 38, 456.

Avery, M. E., and Mead, J. (1959). Surface properties in relation to atelectasis and hyaline membrane disease. American fournal of Diseases of Children, 97, 517.

Bearn, J. G. (1968). The thymus and the pituitary-adrenal axis in anencephaly. A correlation between experimental foetal endocrinology and human pathological observations. British fournal of Experimental Pathology, 49, 136.

Beitins, I. Z., Kowarski, A., Shermeta, D. W., DeLemos, R. A., and Migeon, C. J. (1970). Fetal and maternal secretion rate of cortisol in sheep: diffusion resistance of the placenta. Pediatric Research, 4, 129.

Boughton, K., Gandy, G., and Gairdner, D. (1970). Hyaline membrane disease. II. Lung lecithin. Archives of Disease in Childhood, 45, 311.

Buckingham, S., and Avery, M. E. (1962). Time of appearance of lung surfactant in the foetal mouse. Nature, 193, 688.

Buckingham, S., Heinemann, H. O., Sommers, S. C., and McNary, W. F. (1966). Phospholipid synthesis in the large pulmonary alveolar cell. American fournal of Pathology, 48, 1027.

Cowie, A. T., Daniel, P. M., Prichard, M. M. L., and Tindal, J. S. (1964). Hypophysectomy in pregnant goats and section of the pituitary stalk in pregnant goats and sheep. fournal of Endocrinology, 28, 93.

DeLemos, R. A., Shermeta, D. W., Knelson, J. H., Kotas, R., and Avery, M. E. (1970). Acceleration of appearance of pulmonary surfactant in the fetal lamb by administration of corticosteroids. American Review of Respiratory Diseases, 102, 459.

Farrell, P. M., and Zachman, R. D. (1972). Enhancement of lecithin synthesis and phosphorylcholine glyceride transferase activity in the fetal rabbit lung after corticosteroid administration. (American Pediatric Society and the Society for Pediatric Research, Washington, Annual Meeting, 1972.) (Abst.) Pediatric Research, 6, 337.

Gandy, G., Bradbrooke, J. G., Naidoo, B. T., and Gairdner, D. (1968). Comparison of methods for evaluating surface properties of lung in perinatal period. Archives of Disease in Childhood, 43, 8.

Gandy, G., Jacobson, W., and Gairdner, D. (1970). Hyaline membrane disease. I. Cellular changes. Archives of Disease in Childhood, 45, 289.

Gluck, L., Motoyama, E. K., Smits, H. L., and Kulovich, M. V. (1967). Biochemical development of surface activity in mammalian lung. I. The surface-active phospholipids; the separation and distribution of surface-active lecithin in the lung of the developing rabbit fetus. Pediatric Research, 1, 237.

Humphreys, P. W., and Strang, L. B. (1967). Effects of gestation and prenatal asphyxia on pulmonary surface properties of the foetal rabbit. Fournal of Physiology, 192, 53.

Jost, A., and Picon, L. (1970). Hormonal control of fetal development and metabolism. Advances in Metabolic Disorders, 4, 123.

Kikkawa, Y., Motoyama, E. K., and Cook, C. D. (1965). The ultra-structure of the lungs of lambs. American fournal of Pathology, 47, 877.

Kotas, R. V., and Avery, M. E. (1971). Accelerated appearance of pulmonary surfactant in the fetal rabbit. fournal of Applied Physiology, 30, 358.

Liggins, G. C. (1969). Premature delivery of foetal lambs infused with glucocorticoids. Fournal of Endocrinology, 45, 515.

Liggins, G. C., and Howie, R. N. (1972). A controlled trial of antepartum glucocorticoid treatment for prevention of the respiratory distress syndrome in premature infants. Pediatrics, 50, 515.

Liggins, G. C., and Kennedy, P. C. (1968). Effects of electrocoagulation of the foetal lamb hypophysis on growth and development. Fournal of Endocrinology, 40, 371.

Migeon, C. J., Bertrand, J., and Gemzell, C. A. (1961). The transplacental passage of various steroid hormones in midpregnancy. In Recent Progress in Hormone Research, Vol. 17, p. 207. Ed. by G. Pincus. Academic Press, New York.

Naeye, R. L., Harcke, H. T., and Blanc, W. A. (1971). Adrenal gland structure and the development of hyaline membrane disease. Pediatrics, 47, 650.

Nichols, J., Lescure, O. L., and Migeon, C. J. (1958). Levels of 17-hydroxycorticosteroids and 17-ketosteroids in maternal and cord plasma in term anencephaly. Fournal of Clinical Endocrinology, 18, 444.

Pattle, R. E. (1958). Properties, function, and origin of the alveolar lining layer. Proceedings of the Royal Society B, 148, 217.

Tierney, D. F., Clements, J. A., and Trahan, H. J. (1967). Rates of replacement of lecithins and alveolar instability in rat lungs. American fournal of Physiology, 213, 671.

Correspondence to Dr. M. L. Chiswick, Department of Child Health, St. Mary's Hospital, Hathersage Road, Manchester M13 0JH. 